The Canadian Mineralogist

Vol. 39, pp. 145-151 (2001)

\title{
THE COMPRESSIONAL BEHAVIOR OF P4/n VESUVIANITE
}

\author{
MARIO TRIBAUDINO ${ }^{\S}$ AND MAURO PRENCIPE ${ }^{\S}$ \\ Dipartimento di Scienze Mineralogiche e Petrologiche, Università di Torino, Via Valperga Caluso 35, I-10125, Torino, Italy
}

\begin{abstract}
High-pressure in situ powder-diffraction data were collected on a sample of $P 4 / n$ vesuvianite from Val d'Ala, Piemonte, Italy, between room pressure and 13.2 GPa. No deviation from tetragonal symmetry was found at any pressure. The refined unit-cell parameters show that the highest compressibility is along the $\mathbf{c}$ axis $\left[\beta_{a}=2.00(4) \bullet 10^{-3} \mathrm{GPa}^{-1}\right.$ and $\left.\beta_{c}=2.42(7) \bullet 10^{-3} \mathrm{GPa}^{-1}\right]$. Such behavior, which is inverse to that observed with increasing temperature, is related to weaker bonding along the 4-fold axis owing to the presence of hydrogen bonding and vacancies. A third-order Birch-Murnaghan equation of state was fitted to the retrieved volumes, with $\mathrm{V}_{0}=2859.47(7), \mathrm{K}_{\mathrm{T} 0}=125.5(1.3) \mathrm{GPa}$ and $\mathrm{K}^{\prime}{ }_{\mathrm{T} 0}=4.8(3)$. The compressibility of $P 4 / n$ vesuvianite probably applies to all members of the vesuvianite family.
\end{abstract}

Keywords: vesuvianite, in situ high-pressure powder diffraction, axial compressibility, equation of state.

\section{SOMMAIRE}

Nous avons prélevé in situ les spectres de diffraction sur poudre d'un échantillon de vésuvianite $P 4 / n$ provenant de Val d'Ala, Piemonte, en Italie, à pression allant jusqu'à $13.2 \mathrm{GPa}$. Nous n'avons décelé aucune déviation de la symétrie tétragonale. Les paramètres réticulaires affinés montrent que l'axe de compressibilité maximale est $\mathbf{c}\left[\beta_{a}=2.00(4) \bullet 10^{-3} \mathrm{GPa}^{-1}\right.$ et $\beta_{c}=2.42(7) \bullet 10^{-3}$ $\mathrm{GPa}^{-1}$. Un tel comportement, qui est à l'inverse de l'effet d'une augmentation de la température, résulte des liaisons plus faibles le long de l'axe 4 à cause de la présence de liaisons hydrogène et de lacunes. Nous proposons une équation d'état de type BirchMurnaghan de troisième ordre pour expliquer les volumes de la maille, avec $\mathrm{V}_{0}=2859.47(7), \mathrm{K}_{\mathrm{T} 0}=125.5(1.3) \mathrm{GPa}$ et $\mathrm{K}^{\prime} \mathrm{T} 0=$ 4.8(3). La compressibilité de la vésuvianite $P 4 / n$ pourrait bien s'appliquer à tous les membres de la famille des vésuvianites.

(Traduit par la Rédaction)

Mots-clés: vésuvianite, diffraction sur poudre in situ à pression élevée, compressibilité axiale, équation d'état.

\section{INTRODUCTION}

Several investigations have recently been performed on minerals of the vesuvianite family. The main objective of these studies was to investigate detailed structural features and cation occupancies in this complex phase (Giuseppetti \& Mazzi 1983, Fitzgerald et al. 1986a, b, Allen \& Burnham 1992, Groat et al. 1992a, b, 1994a, b, 1996, Lager et al. 1999, Armbruster \& Gnos 2000a, b). Although in most cases vesuvianite displays a $P 4 / n n c$ space group, a few lower-symmetry varieties were documented, mostly in low-temperature metamorphic environments. Some of these cases of lower-symmetry vesuvianite were found to have tetragonal symmetry, but characteristically crystallize in space group $P 4 / n$ or $P 4 n c$ (Giuseppetti \& Mazzi 1983, Pavese et al. 1998, Tribaudino \& Prencipe 1999, Armbruster \& Gnos 2000a, b). For these samples, the lowering of sym- metry is driven by cation order within the sites along the four-fold axis. Other samples of low-symmetry vesuvianite were found to be strongly biaxial varieties, which clearly deviate from tetragonal symmetry (Groat et al. 1993). Veblen \& Wiechmann (1991) found a domain texture of pseudomerohedral twins of monoclinic $P 2 / n$ symmetry, possibly related to a ferroelastic transition from tetragonal symmetry. The evolution of the optical birefringence with temperature enabled Groat $e t$ al. (1995) to determine a critical temperature of $780 \mathrm{~K}$ for the ferroelastic transition from monoclinic to tetragonal. An extremely small spontaneous strain was determined using high-temperature powder-diffraction measurements, but it was not possible to determine precise unit-cell parameters and thermal expansion. Apart from the paper by Groat et al. (1995), most of the work on vesuvianite has been done at ambient conditions. Recently, we carried out an in situ structural investiga-

$\S \quad$ E-mail addresses: triba@dsmp.unito.it, prencipe@dsmp.unito.it 
tion at high temperature (Tribaudino \& Prencipe 1999), in which the measured thermal expansion of $P 4 / n$ vesuvianite was found to be significantly higher along the $\mathbf{c}$ than along the a axis; moreover, in our analysis of the atomic displacement parameters with temperature, we suggested that there is an absence of positional disorder and no evidence of a deviation from the space group proposed. To determine the response of the vesuvianite structure to non-ambient conditions, high-pressure data are required. In minerals, an inverse behavior of cell parameters with pressure and temperature is observed, but deviations from inverse behavior were observed in several complex minerals like feldspars (Angel 1994). High-pressure data on vesuvianite also are needed to better constrain the thermodynamic behavior of the mineral; vesuvianite is present in many metamorphic environments, and equilibrated up to pressures of $\mathrm{P}=1.0$ $\mathrm{GPa}$ at $\mathrm{T}=800^{\circ} \mathrm{C}$ (Ito \& Arem 1970). In thermodynamic modeling of vesuvianite-bearing parageneses, compressional data are needed that were previously only estimated (Gottschalk 1997, Holland \& Powell 1998). Experimental high-pressure results are needed to improve the modeling of metamorphic reactions involving vesuvianite and to verify the consistency of the estimates.

In this paper, we report the results of an in situ highpressure powder-diffraction investigation by means of synchrotron radiation. The investigation was done on the same sample as the one thoroughly characterized by $\mathrm{X}$-ray and neutron diffraction and detailed chemical analysis by Pavese et al. (1998) and used in the hightemperature in situ investigation by Tribaudino \& Prencipe (1999). In this paper, we discuss the feasibility of an in situ high-pressure powder-diffraction investigation of a complex mineral like vesuvianite, perform a detailed comparison with the high-temperature behavior, and verify the opposite effect of temperature and pressure.

\section{EXPERIMENTAL}

In situ high-pressure powder-diffraction data were collected using synchrotron radiation at ESRF (European Synchrotron Radiation Facility, ID09 beamline). We used a sample of Val d'Ala vesuvianite, from the same specimen used previously for neutron (Pavese $e t$ al. 1998) and high-temperature in situ X-ray diffraction (Tribaudino \& Prencipe 1999). For this sample, the composition was found to be $\mathrm{Ca}_{18.9} \mathrm{Al}_{10.0} \mathrm{Mg}_{2.0} \mathrm{Fe}^{3+}{ }_{1.1}$ $\mathrm{Si}_{18.0} \mathrm{O}_{69.1}(\mathrm{OH})_{8.9}$; optically, it shows moderate zoning, no anomalous birefringence, uniaxial character and a negative optical sign. The presence of boron was ruled out in this sample, as it falls within the B-free vesuvianite group according to the criteria reported by Groat $e t$ al. (1992a, 1998). Observations by transmission electron microscopy, neutron and $\mathrm{X}$-ray investigations showed sharp reflections violating the presence of glide planes parallel to the 4 -fold axis. The sample was loaded
TABLE 1. STATISTICS OF RIETVELD REFINEMENTS OF VESUVIANITE AT VARIOUS PRESSURES

\begin{tabular}{lcccc}
\hline $\mathbf{P}$ & $w R_{p} \%$ & $R_{p} \%$ & $D W d$ & $\chi^{2}$ \\
\hline Room pressure & 1.0 & 0.7 & 0.50 & 0.4 \\
$1.5 \mathrm{GPa}$ & 1.4 & 1.0 & 0.33 & 1.2 \\
3.6 & 0.9 & 0.7 & 0.63 & 0.5 \\
5.3 & 1.0 & 0.7 & 0.56 & 0.5 \\
7.4 & 1.2 & 0.9 & 0.51 & 0.7 \\
9.4 & 1.6 & 0.7 & 0.45 & 0.5 \\
10.7 & 1.3 & 0.9 & 0.56 & 0.9 \\
13.2 & 1.4 & 0.9 & 0.40 & 0.9 \\
& & & & \\
\hline
\end{tabular}

into a diamond anvil cell with $\mathrm{N}_{2}$ as pressure-transmitting medium. The diffraction patterns were collected at a wavelength $\lambda$ of $0.4526(1) \AA$, with a position-sensitive detector. A detailed description of the experimental conditions and the integration of the diffraction patterns can be found in Tribaudino et al. (2000).

\section{RESUlts AND Discussion}

\section{Analysis of powder-diffraction data}

Rietveld refinement of the collected diffraction patterns was performed using the GSAS refinement package (Larson \& Von Dreele 1986). Owing to the structural complexity, atomic coordinates were not refined at any pressure, and a LeBail procedure (LeBail $e t$ al. 1988), as implemented in GSAS, was followed instead. Scale factor, background parameters using a Fourier-cosine series with 20 terms, profile coefficients according to a pseudo-Voigt function, and cell parameters were refined. For all the spectra, the analysis was performed in the $2 \theta$ range 5 to $18^{\circ}$, excluding regions where peaks of the high-pressure phases of $\mathrm{N}_{2}$ (Olijnyk 1990) were present. Relevant statistics of the Rietveld refinement are reported in Table 1; the quality of the fits is essentially the same at all pressures; the values of the goodness of fit $\left(\chi^{2}\right)$ indicate that the model used (in particular, the specific profile-shape function) fits the observed profiles well (Fig. 1). The relatively low values of the Durbin-Watson $d$ statistic $(D W d$; Hill \& Flack 1987) could be due to some serial correlation of the observed intensities, suggesting an underestimation of the standard deviation of all the refined parameters. Reducing the number of observations by a factor of two had the effect of increasing $D W d$, leading to more realistic estimations of error and to $\chi^{2}$ values closer to 1 ; the drawback was a general increase of the correlation among background and profile coefficients, together with difficulties in reaching convergence. Several attempts were made to test for possible false minimum: refinements starting from different conditions, established by modifying profile and background coefficients, did not produce significant changes in the refined unit-cell parameters. Moreover, to check the evolution 


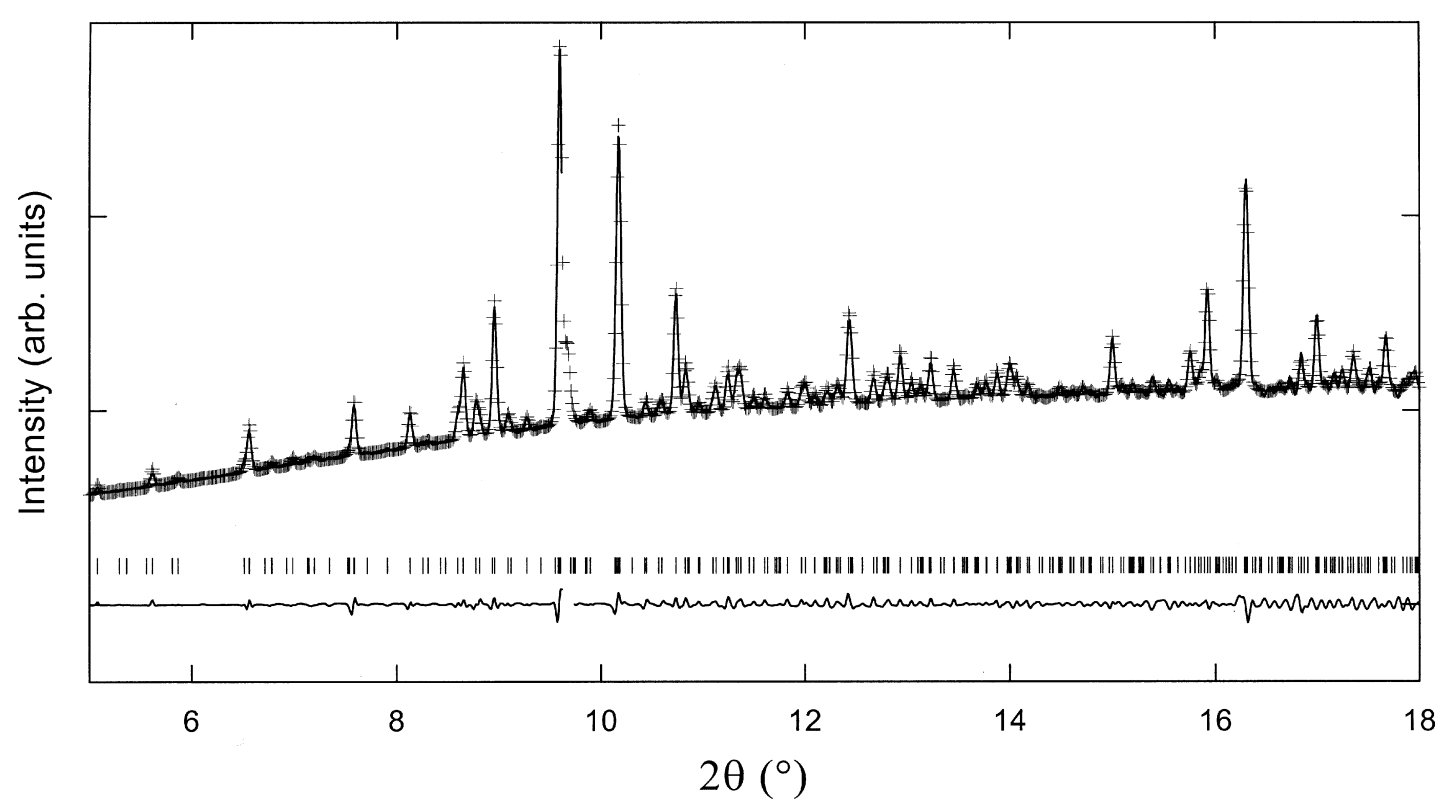

FIG. 1. The diffraction pattern of vesuvianite at $\mathrm{P}=7.4 \mathrm{GPa}$; measured (crosses) and calculated (continuous line) intensities, positions of the reflections and difference curve between observed and calculated spectra are shown. The difference and calculated curves are not shown in the region excluded because of the presence of a $\mathrm{N}_{2}$ peak.

of such parameters, several low-angle unique reflections were followed with pressure, indicating, although with lower precision, the same cell-parameter evolution as obtained from Rietveld analysis. A further check was done by conventional X-ray diffraction on a Guinier camera $\left(\mathrm{CuK} \alpha_{1}, \lambda=1.54063 \AA\right)$ at ambient conditions, with quartz as an internal standard to fix the zero position of the diffractometer. The diffraction pattern was refined using the Rietveld method and the LeBail procedure (LeBail et al. 1988). Scale factors, background, profile and cell parameters were refined. The cell parameters obtained [ $a$ 15.5530(4) $\AA, c 11.8350(3) \AA]$ are in reasonable agreement with those from the synchrotron data at room pressure, but with the uncompressed sample loaded in the diamond anvil cell. It is to be noted, however, that the difference between the cell parameters measured at room pressure with the two different experimental setups is much higher than the estimated standard deviation. This difference reflects the actual precision of the Rietveld refinement procedure, which is reported to be generally lower than that which would appear from the estimated standard deviations alone (Hill 1992). The cell parameters at various pressures are reported in Table 2.

\section{High-pressure and high-temperature behavior}

The fact that the sample examined in this work is the same as that investigated at high temperature by
TABLE 2. UNIT-CELL PARAMETERS AND VOLUME OF VESUVIANITE AT VARIOUS PRESSURES

\begin{tabular}{llll}
\hline $\mathrm{P}$ & \multicolumn{1}{c}{$a$} & \multicolumn{1}{c}{$c$} & \multicolumn{1}{c}{$V$} \\
\hline Room pressure & $15.547(1) \AA$ & $11.8296(2) \AA$ & $2859.47(7) \AA^{3}$ \\
$1.5 \mathrm{GPa}$ & $15.4928(2)$ & $11.7747(3)$ & $2826.23(9)$ \\
3.6 & $15.4284(2)$ & $11.7123(2)$ & $2787.93(6)$ \\
5.3 & $15.3662(2)$ & $11.6544(2)$ & $2751.85(6)$ \\
7.4 & $15.3003(2)$ & $11.5941(3)$ & $2714.17(6)$ \\
9.4 & $15.2452(2)$ & $11.5442(2)$ & $2683.06(5)$ \\
10.7 & $15.2049(3)$ & $11.5075(3)$ & $2660.41(8)$ \\
13.2 & $15.1369(3)$ & $11.4549(7)$ & $2624.6(1)$ \\
& & & \\
\hline
\end{tabular}

Tribaudino \& Prencipe (1999) enables a comparison of the high-temperature and high-pressure behavior.

Data on the compression of cell parameters, in Figure 2, show evidence of a higher compression along the c than along the a axis; the linear compressibility coefficients are $\beta_{a}=2.00(4) \cdot 10^{-3} \mathrm{GPa}^{-1}$ and $\beta_{c}=2.42(7) \cdot 10^{-3}$ $\mathrm{GPa}^{-1}$. Figure 2a shows also that the cell parameters do not follow a linear variation with pressure; a secondorder polynomial was used to fit the cell parameters, giving the following results:

$$
\begin{aligned}
& a=15.547(2)-3.55(8) \cdot 10^{-2 *} \mathrm{P}+3.3(6) \cdot 10^{-4 *} \mathrm{P}^{2}, \\
& \mathrm{R}=0.9997
\end{aligned}
$$



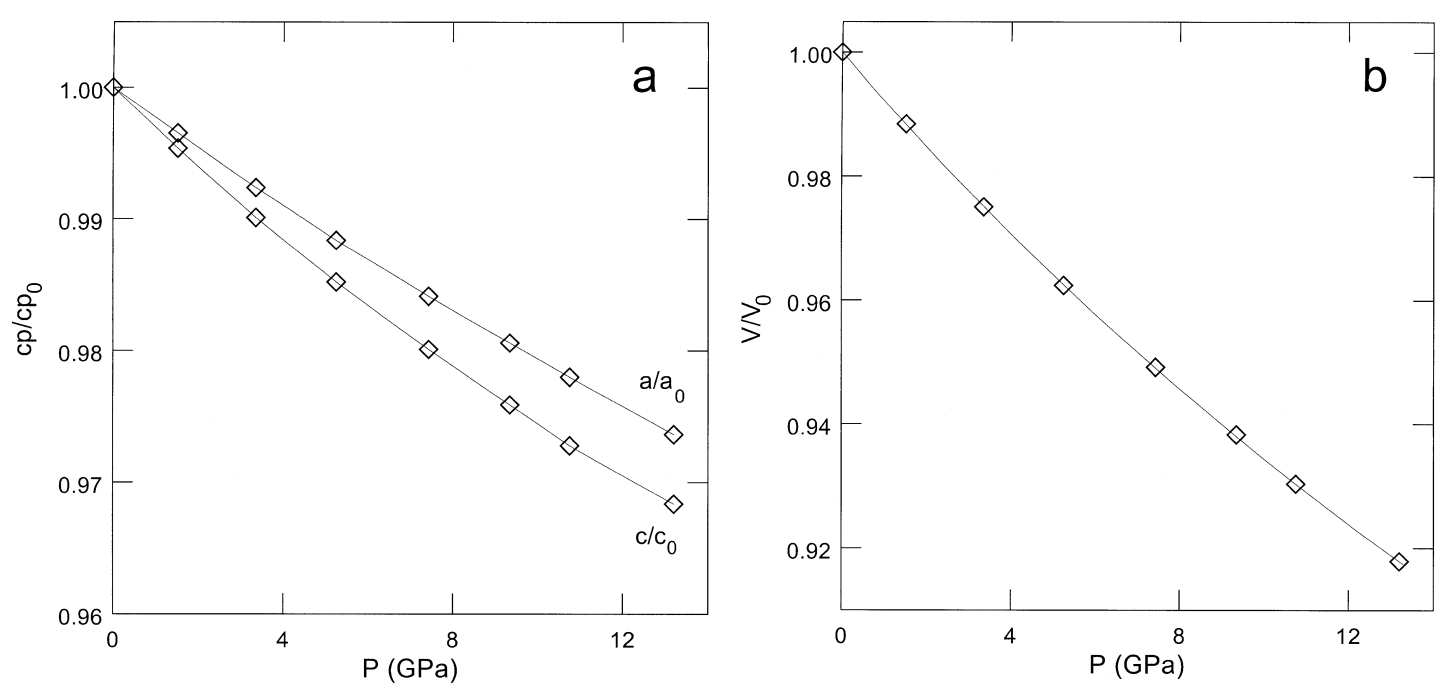

FIG. 2. a) Ratio of a cell parameter (cp) at a given pressure with its value at ambient conditions ( $\left.\mathrm{cp}_{0}\right)$ versus $P$, b) $\mathrm{V} / \mathrm{V}_{0}$ versus $P$.

$$
\begin{aligned}
& c=11.829(2)-3.57(8) \cdot 10^{-2 *} \mathrm{P}+5.5(6) \cdot 10^{-4 *} \mathrm{P}^{2}, \\
& \mathrm{R}=0.9997
\end{aligned}
$$

Addition of higher-order terms did not improve the fit, and the coefficients of the higher-order terms were not significant.

The difference in the compressibility along the two axes is significant and well beyond error. Increasing temperature shows that the higher expansion occurs along the $\mathbf{c}$ axis $\left(\alpha_{a}=10.4(3) \cdot 10^{-6} \mathrm{~K}^{-1}\right.$ and $\alpha_{c}=$ $12.9(3) \cdot 10^{-6} \mathrm{~K}^{-1}$; Tribaudino \& Prencipe 1999). Hazen \& Finger (1982) demonstrated an inverse relationship in several compounds between the effect of pressure and temperature on a specific structural parameter, revealed by a linear plot of $\mathrm{V} / \mathrm{V}_{0}$ versus the investigated parameter at high pressure and temperature. An inverse relationship is the rule in simple structures, whereas in complex ones it has to be verified. In Figure 3, a linear plot of the cell parameters versus $\mathrm{V} / \mathrm{V}_{0}$ is shown, indicating an inverse relationship of cell parameters.

At high temperature, the higher expansion along the c axis was ascribed to the presence along the 4-fold axis of channel-like configurations, along which is a sequence of cation - oxygen - hydrogen atoms (strings, according to Allen \& Burnham 1992), with sites not fully occupied, since full occupancy is not compatible with crystal-chemical requirements. Along the strings, hydrogen bonding is present, as well as repulsion due to the cations along the c axis. Pavese et al. (1998, Fig. 2) provided an overview of the relevant structural configurations. Therefore, it is likely that with increasing temperature, higher expansion occurs along the string direction, i.e., along the $\mathbf{c}$ axis. The same argument applies to explain the higher compressibility along the $\mathbf{c}$ axis. Prewitt \& Downs (1998) observed, in fact, that higher compressibility occurs along the direction that has the weaker bonds; this in fact occurs in vesuvianite, which has weaker bonding along the $\mathbf{c}$ axis.

The volume data from ambient pressure to $\mathrm{P}=13.2$ $\mathrm{GPa}$ were fitted to a third-order Birch-Murnaghan equation of state:

$$
\begin{aligned}
& \mathrm{P}=3 / 2 \mathrm{~K}_{\mathrm{T} 0}\left[\left(\mathrm{~V}_{0} / \mathrm{V}\right)^{7 / 3}-\left(\mathrm{V}_{0} / \mathrm{V}\right)^{5 / 3}\right] \\
& \left\{1+3 / 4\left(4-\mathrm{K}^{\prime}{ }_{\mathrm{T} 0}\right)\left[\left(\mathrm{V}_{0} / \mathrm{V}\right)^{2 / 3}-1\right]\right\}
\end{aligned}
$$

The values for the volume at $\mathrm{P}=0 \mathrm{GPa}\left(\mathrm{V}_{0}\right)$, for the isothermal bulk modulus $\left(\mathrm{K}_{\mathrm{T} 0}\right)$, and for its first pressure derivative $\left(\mathrm{K}^{\prime}{ }_{\mathrm{T} 0}\right)$ were refined simultaneously; errors from Rietveld refinement were given for the experimental volumes, whereas a $0.1 \mathrm{GPa}$ error was given to the experimental pressure. The refined values are $\mathrm{V}_{0}=$ 2859.47(7), $\mathrm{K}_{\mathrm{T} 0}=125.5(1.3) \mathrm{GPa}$ and $\mathrm{K}^{\prime} \mathrm{T} 0=4.8(3)$ with a $w \chi^{2}=1.24$, indicating that the standard deviations for the volume and the pressure are reasonable. The presence of a $\mathrm{K}_{\mathrm{T} 0}^{\prime}$ significantly different from 4 , and the need for a third-order equation of state, were clearly demonstrated by the presence of systematic residuals in the high-pressure data, where the $\mathrm{K}^{\prime}{ }_{\mathrm{T} 0}$ value was constrained to 4 . Refinement constraining the $V_{0}$ value did not result in changes that are significant within error. Fitting a parameterized third-order BirchMurnaghan equation of state to the cube of the edge lengths resulted in $a_{0}=15.547(1) \AA, \mathrm{K}_{\mathrm{a}}=140.8(1.4)$, $\mathrm{K}_{\mathrm{a}}^{\prime}=4.0(3)$ and $c_{0}=11.830(1), \mathrm{K}_{\mathrm{c}}=103.0, \mathrm{~K}_{\mathrm{c}}^{\prime}=5.8(3)$. It is of interest that the curvature in the pressure - volume trend is mostly due to the high $\mathrm{K}^{\prime}$ value in the c cell parameter. The calculated equations of state for volume and cell parameters are shown in Figures 2a and 

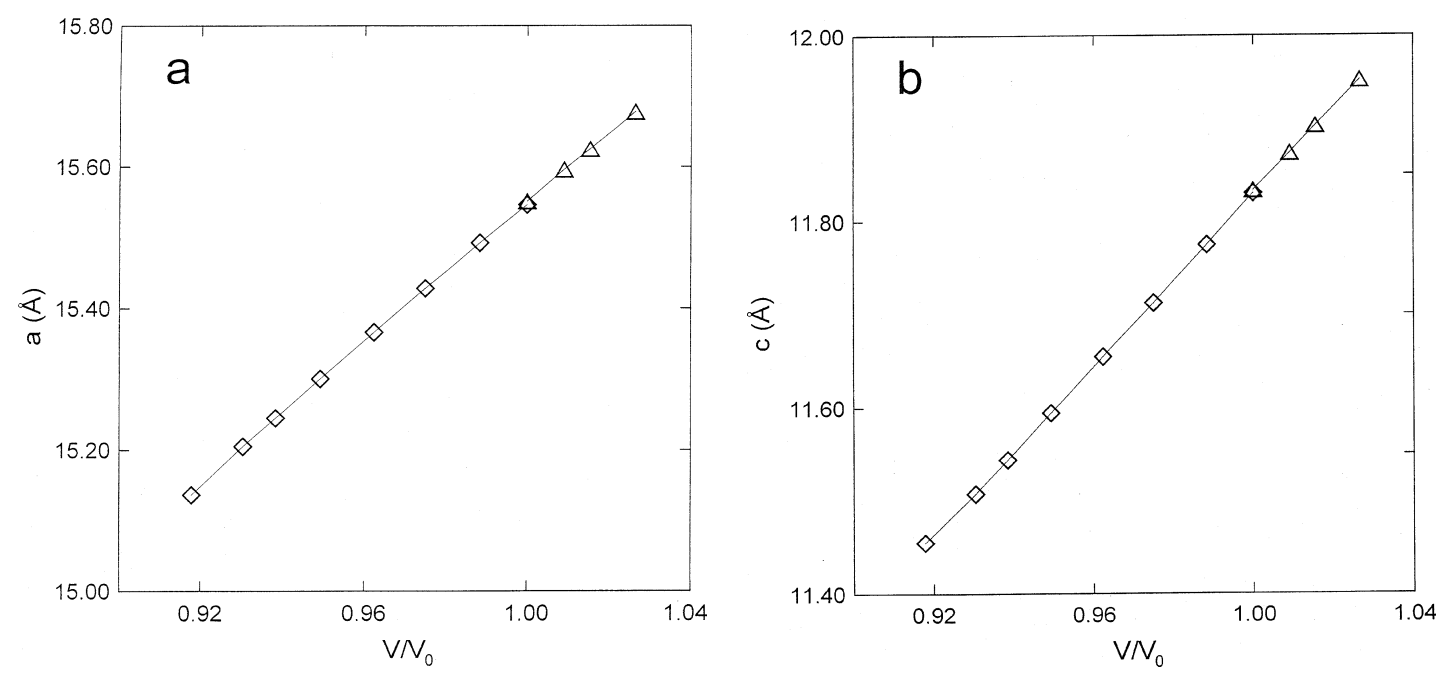

FIG. 3. a) The $a$ cell parameter versus $\mathrm{V} / \mathrm{V}_{0}$ at high pressure and temperature. b) The $c$ cell parameter versus $\mathrm{V} / \mathrm{V}_{0}$ at high pressure and temperature. High-pressure data: diamonds, this work; high-temperature data: triangles, Tribaudino \& Prencipe (1999).

b, compared with the observed data. The high quality of the fit confirms the reliability of the refined parameters.

The compressibility data from this work can be compared with previous estimates on the compressibility of vesuvianite (Gottschalk 1997, Holland \& Powell 1998). These were done using the following equation that relates the bulk modulus with the molar volume and the mean atomic weight (Wang 1978) in non-isostructural materials:

$$
\mathrm{K}_{\mathrm{T} 0} * \mathrm{~V}_{\mathrm{m}}{ }^{4}=\mathrm{k}
$$

In the above equation, $\mathrm{k}$ ' is a constant for all structures with the same mean atomic weight (M, molecular weight divided the number of atoms in the formula unit); in turn, the k' constant was related to $\mathrm{M}$ by an empirical equation (Gottschalk 1997), calculated by fitting of a set of mineral phases in which the compressibility was known:

$$
\begin{aligned}
& -\ln \mathrm{k}^{\prime}=-6.90776-1.92764 \mathrm{M}+0.40009 \mathrm{M}^{1.5} \\
& -0.02321 \mathrm{M}^{2}
\end{aligned}
$$

By use of such an equation, bulk moduli of 134 and 124 $\mathrm{GPa}$ are calculated for vesuvianite, respectively, with and without hydrogen atoms, in reasonable agreement with the experimental results.

We contend that the compressibility of $P 4 / n$ vesuvianite, as determined in this work, applies to all minerals of the vesuvianite family. This claim should clearly be verified experimentally. However, we contend that in the absence of other data, the observed differences should not be high. In minerals of the vesuvianite family, the chemical variability in the major cations $(\mathrm{Ca}, \mathrm{Si}$, Al) is relatively limited, with few exceptions, at least when compared to the range of isomorphous substitution possible in other structures, like pyroxenes and garnets. A model proven to be rather successful to predict trends in the bulk modulus within a given structural family assumes that it is inversely proportional to the molar volume (Wang 1978), i.e., $\mathrm{K}_{\mathrm{T} 0} \mathrm{~V}=$ constant. As cation ordering affects only selected polyhedra, we can make the assumption that $P 4 / n$ and $P 4 / n n c$ space groups are essentially isostructural. As a consequence of the relatively limited chemical variability in major cations, changes in the molar volume are rather small within the vesuvianite family. The predicted variability from the compilation of structural data by Groat et al. (1992a), would, assuming the constant obtainable by this study, be between $\mathrm{K}_{\mathrm{T} 0}=123.5$ and $127.0 \mathrm{GPa}$, i.e., almost within experimental uncertainty.

\section{Cation ordering and ferroelastic phase-transition}

One of the problems not yet solved relating the phase transition in vesuvianite is the relation of tetragonal phases to the non-tetragonal varieties. In an investigation of the transition to monoclinic vesuvianite, Groat et al. (1993) showed a continuous ferroelastic phasetransition from the high-symmetry space-group $P 4 / n n c$ to the monoclinic space group $P 2 / n$. From a simple group-subgroup argument, the symmetry $P 4 / n$ of the sample used in this work is intermediate in the above sequence. It is not clear, however, whether natural cat- 
ion-ordered $P 4 / n$ vesuvianite is actually an intermediate step in the $P 4 / n n c-P 2 / n$ reduction in symmetry. If so, cation ordering would be preliminary to the decrease in symmetry. The physical mechanism for the transformation would begin with cation ordering, followed by some kind of displacive collapse. The results for hightemperature measurements of the birefringence suggest in fact that the mechanism is driven by some kind of displacive transition with a critical temperature near 780 $\mathrm{K}$, but the lack of structural refinement of monoclinic varieties hampers the determination of the cation order in monoclinic vesuvianite.

In phase transitions in minerals, the empirical rule of an inverse behavior of pressure and temperature has been observed (Hazen \& Finger 1982), i.e., if a given low-symmetry phase transforms to a high-symmetry form with increased temperature, the high-symmetry phase transforms with pressure to the low-symmetry phase. Since Groat et al. (1995) have found that the transition from monoclinic to tetragonal symmetry in vesuvianite occurs at high temperature, we suggest that $P 4 / n$ vesuvianite may undergo a phase transition at some high pressure. Our sample is suitable for such an investigation: its composition is very close to that of the samples used for an investigation of ferroelastic phasetransition in vesuvianite by Groat et al. (1995), and the same glide-plane violations are present. However, our analysis of a sequence of well-separated low-angle diffraction peaks does not show any evidence of peak splitting or enlargement with pressure, and no change in the relative intensity of such reflections (which could suggest the occurrence of a phase transition) was observed. No evidence of a phase transition can be obtained from these results. We suggest, therefore, that the tetragonalto-monoclinic ferroelastic transition does not necessarily go through a cation-ordering stage, in agreement with the observation by Groat et al. (1993) of the lack of correlation between the intensity of glide-violating reflections and the spontaneous strain due to the transition.

\section{ACKNOWLEDGEMENTS}

Marco Bruno and Davide Levy are gratefully acknowledged for help during experimental collection. Reviews from Ulrich Bismayer and Lee A. Groat greatly improved the manuscript. This work was supported by a CNR grant.

\section{REFERENCES}

Allen, F.M. \& Burnham, C.W. (1992): A comprehensive structure model for vesuvianite: symmetry variations and crystal growth. Can. Mineral. 30, 1-18.

ANGEL, R.J. (1994): Feldspars at high pressure. In Feldspars and their Reactions (I. Parsons, ed.). Kluwer, Dordrecht, The Netherlands (271-312).
Armbruster, T. \& GNOS, E. (2000a): $P 4 / n$ and $P 4 n c$ longrange ordering in low-temperature vesuvianites. Am. Mineral. 85, 563-569.

$\&$

(2000b): Tetrahedral vacancies and cation ordering in low-temperature Mn-bearing vesuvianites: indication of a hydrogarnet-like substitution. Am. Mineral. 85, 570-577.

Fitzgerald, S., Rheingold, A.L. \& Leavens, P.B. (1986a): Crystal structure of a $\mathrm{Cu}$-bearing vesuvianite. Am. Mineral. 71, 1011-1014.

$\&$ (1986b): Crystal structure of a non-P4/nnc vesuvianite from Asbestos, Quebec. Am. Mineral. 71, 1483-1488.

GiuseppetTi, G. \& MAZZI, F. (1983): The crystal structure of a vesuvianite with $P 4 / n$ symmetry. Tschermaks Mineral. Petrogr. Mitt. 31, 277-288.

GotTSCHALK, M. (1997): Internally consistent thermodynamic data for rock forming minerals in the system $\mathrm{SiO}_{2}-\mathrm{TiO}_{2}-$ $\mathrm{Al}_{2} \mathrm{O}_{3}-\mathrm{CaO}-\mathrm{MgO}-\mathrm{FeO}-\mathrm{K}_{2} \mathrm{O}-\mathrm{Na}_{2} \mathrm{O}-\mathrm{H}_{2} \mathrm{O}-\mathrm{CO}_{2}$. Eur. J. Mineral. 9, 175-223.

Groat, L.A., Bismayer, U. \& Güttler, B. (1995): A ferroelastic phase transition in vesuvianite. Phase Transitions 55, 217-227.

, Hawthorne, F.C. \& Ercit, T.S. (1992a): The chemistry of vesuvianite. Can. Mineral. 30, 19-48.

$\&$ (1992b): The role of fluorine in vesuvianite: a crystal-structure study. Can. Mineral. 30, 1065-1075.

$\&$ (1994a): Excess $Y$-group cations in the crystal structure of vesuvianite. Can. Mineral. 32, 497-504. \& (1994b): The incorporation of boron into the vesuvianite structure. Can. Mineral. 32, 505-523.

\& GRICE, J.D. (1998): Wiluite, $\overline{C a}_{19}(\overline{\mathrm{Al}}, \overline{\mathrm{Mg}}, \overline{\mathrm{Fe}}, \mathrm{Ti})_{13}(\mathrm{~B}, \mathrm{Al},)_{5} \mathrm{Si}_{18} \mathrm{O}_{68}(\mathrm{O}, \mathrm{OH})_{10}$, a new mineral species isostructural with vesuvianite, from the Sakha Republic, Russian Federation. Can. Mineral. 36, 1301-1304.

\& Putnis, A. (1993): The symmetry of vesuvianite. Can. Mineral. 31, 617-635.

, Lager, G.A., Schultz, A.J. \& ERcit, T.S. (1996): X-ray and neutron crystal-structure refinements of a boron-bearing vesuvianite. Can. Mineral. 34, 1059-1070.

HAZEN, R.M. \& FIngER, L.W. (1982): Comparative Crystal Chemistry. John Wiley \& Sons, Chichester, U.K. 
HiLL, R.J. (1992): Rietveld refinement round robin. I. Analysis of standard X-ray and neutron data for $\mathrm{PbSO}_{4}$. J. Appl. Crystallogr. 25, 589-610.

\& FLACK, H.D. (1987): The use of Durbin Watson d statistics in Rietveld analysis. J. Appl. Crystallogr. 20, 356361.

Holland, T.J.B. \& Powell, R. (1998): An internally consistent thermodynamic data set for phases of petrological interest. J. Metamorph. Geol. 16, 309-343.

Ito, J. \& AREM, J.E. (1970): Idocrase: synthesis, phase relations and crystal chemistry. Am. Mineral. 55, 880-912.

Lager, G.A., XIE, Q., Ross, F.K., Rossman, G.R., Armbruster, T., Rotella, F.J. \& SchulTZ, A.J. (1999): Hydrogen-atom positions in P4/nnc vesuvianite. Can Mineral. 37, 763-768.

Larson, A.C. \& Von Dreele, R.B. (1986): GSAS: General Software Analysis System manual. Los Alamos National Lab., Rep. LA-UR:86-87.

LeBail, A, Duroy, H. \& Fourquet, J.L. (1988): Ab-initio structure determination of $\mathrm{LiSbWO}_{6}$ by X-ray powder diffraction. Mater. Res. Bull. 23, 447-452.

OLIJNYK, H. (1990): High pressure X-ray diffraction studies on solid $\mathrm{N}_{2}$ up to $43.9 \mathrm{GPa}$. J. Chem. Phys. 93, 8968-8972.
Pavese, A., Prencipe, M., Tribaudino, M. \& Sørensen AAGAARD, S. (1998): X-ray and neutron single-crystal study of $P 4 / n$ vesuvianite. Can. Mineral. 36, 1029-1037.

PrewitT, C.T. \& Downs, R.T. (1998): High-pressure crystal chemistry. In Ultrahigh-Pressure Mineralogy: Physics and Chemistry of the Earth's Deep Interior (R.J. Hemley, ed.). Rev. Mineral. 37, 283-317.

Tribaudino, M. \& PREnCiPE, M. (1999): A high temperature in situ single-crystal study of $P 4 / n$ vesuvianite. Eur. J. Mineral. 11, 1037-1042.

, BRUNO, M. \& LEVY, D. (2000): High pressure behaviour of $\mathrm{Ca}$-rich $C 2 / c$ clinopyroxenes along the join diopside-enstatite $\left(\mathrm{CaMgSi}_{2} \mathrm{O}_{6}-\mathrm{Mg}_{2} \mathrm{Si}_{2} \mathrm{O}_{6}\right)$. Phys. Chem. Minerals 27, 656-664.

Veblen, D.R. \& Wiechmann, M.J. (1991): Domain structure of low-symmetry vesuvianite from Crestmore, California. Am. Mineral. 76, 397-404.

WANG, H.F. (1978): Elastic constant systematics. Phys. Chem. Minerals 3, 251-261.

Received March 13, 2000, revised manuscript accepted January 6, 2001. 